Article

\title{
A Newly Hybrid Method Based on Cuckoo Search and Sunflower Optimization for Optimal Power Flow Problem
}

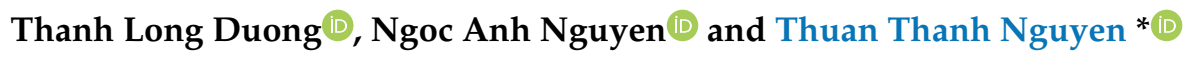 \\ Faculty of Electrical Engineering Technology, Industrial University of Ho Chi Minh City, Ho Chi Minh City \\ 700000, Vietnam; duongthanhlong@iuh.edu.vn (T.L.D.); nguyenngocanh@iuh.edu.vn (N.A.N.) \\ * Correspondence: nguyenthanhthuan@iuh.edu.vn
}

Received: 3 May 2020; Accepted: 27 June 2020; Published: 30 June 2020

\begin{abstract}
The paper proposes a new hybrid method based on cuckoo search (CSA) and sunflower optimization (SFO) approach (called HCSA-SFO) for improving the performance of solutions in the optimization power system operation problem. In the power system, the optimal power flow (OPF) problem is one of the important factors which usually minimizes total cost and total active power losses while satisfying all constraints of the output power of generators, the voltage at buses, power flow on branches, the capacity of capacitor banks and steps of transformer taps. HCSA-SFO utilizes the mutation and selection mechanism in the SFO algorithm to replace the Lévy flights function in CSA. Hence, this makes HCSA-SFO avoid the fixed step size in the CSA from that can reduce run time and improve the quality of solution for the HCSA-SFO algorithm in the OPF problem. The proposed hybrid technique is simulated on the 30-buses and 118-buses systems. The obtained simulation results from the suggested technique are compared to many other approaches. The result comparisons in different cases showed that the suggested HCSA-SFO can achieve a better result than many other optimization approaches. Therefore, the suggested HCSA-SFO is also an effective approach for dealing with the OPF problem.
\end{abstract}

Keywords: sunflower optimization; optimal power flow; total fuel cost; cuckoo search algorithm; total active power losses

\section{Introduction}

Electric companies are constantly striving to find ways for improving effectiveness in the operation of power systems to decrease the production cost while still satisfying all security constraints. The optimal power flow (OPF) problem still plays a major role in power system operation, and it has been continuously studied for enhancing effectiveness in solving the above problems. The OPF is a nonlinear optimization issue with several parameters and numerous equations and also inequality constraints. The parameters of the OPF problem are that power generation outputs, switchable capacitor banks, voltages at buses and tap changers of transformers, while the equations and inequality constraints are real and reactive power balance constrains, the maximum and minimum limits of reactive and real power outputs, the voltage at buses, the capacity of capacitor banks and steps of transformer taps. Therefore, the OPF in power systems is one of a more difficult topic which needs an effective method for solving. Several traditional methods and optimization algorithms have been used to find an OPF solution.

A lot of traditional methods in dealing with the problem of OPF were proposed with aims of minimizing fuel cost, including method of interior point [1], a technique of nonlinear programming [2], a linear programming technique [3], quadratic programming [4] and a newton-based approach [5]. 
Although the traditional optimization methods have obtained some results in solving the OPF problem, they still show limits for operation in modern power systems which is always a nonlinear optimization issue. Thus, developing an effective optimization method for handling the nonlinear problems of OPF is a vital subject for the research groups of power system optimization.

Recently, many Artificial Intelligence algorithms have been proposed as one alternative promising option for dealing with the problem of OPF. In ref. [6], an improved evolutionary programming (IEP) was introduced in dealing with the OPF problem, in which the mutation and selection techniques were implemented based on Gaussian and Cauchy distributions and the probabilistic. Another search based on differential evolution (DE) to solve the OPF problem has been proposed in [7]. The DE algorithm was tested on power systems with two single-objective functions and a multiobjective function. The results have shown that DE is available to find a performance solution for the OPF problem. A particle swarm optimization (PSO) approach was presented in [8] for dealing with OPF with the multiobjective function. Wherein, a fuzzy membership function was used to choose the best value from the list of Pareto optimal values. Other optimization methods were proposed towards the problem of OPF, such as gravitational search algorithm (GSA) [9-11], differential evolutionary methods [12,13], krill herd algorithm [14], artificial bee colony method [15], an imperialist competitive method [16], an approach of biogeography-based optimization [17], Jaya algorithm [18], a hybrid PSO-GSA approach [19], a technique of improved colliding bodies optimization [20], harmony search method [21], an approach of teaching-learning-optimization [22] and the technique of black-hole-based optimization [23]. In [24], the OPF in a normal and contingent case was solved using the algorithm of improved genetics. Another method based on modified sine-cosine was proposed in [25]. The authors in [26] suggested the method of glowworm swarm optimization to solve the problem of OPF. The problem of OPF with multiobjective function was presented in [27-35].

Recently, the cuckoo search algorithm (CSA) [36,37] and sunflower optimization [38] have been proposed as two other optimization approaches in dealing with the optimization problem in power systems. Although both CSA and SFO were capable of solving the optimization problem, they showed some drawbacks of balancing exploration and exploitation when performing optimization methods in large-scale systems. Finding a suitable balance between exploitation and exploration from a combination CSA and SFO algorithms promises an effective technique for the OPF problem. With this point of view, this paper suggested a hybrid CSA and SFO (HCSA-SFO) technique in dealing with the problem of OPF. The main objective of the suggested technique is to replace the Lévy flight function in CSA using a mutation and selection mechanism in the SFO algorithm to avoid the fixed step size in the CSA, hence increasing the effective global search and improving the quality of the obtained solution. The suggested technique is simulated on the standard 30-buses and 118-buses system. Its results are compared to other methods. The simulation results show that HCSA-SFO is an effective technique to solve the OPF problem in a complex and large-scale system.

The outstanding points of the suggested technique can be listed as follows:

- Dealing with OPF frameworks with several objective functions conditions using a hybrid HCSA-SFO algorithm;

- The HCSA-SFO utilizes the mutation and selection mechanism to follow the best orientation to the sun of sunflowers from the SFO algorithm to replace the Lévy flights function in CSA. This technique helps HCSA-SFO to avoid the fixed step size in the CSA, hence the run time is reduced and the quality of solution for the HCSA-SFO algorithm in the OPF problem is improved;

- The simulation result is validated on the standard 30-buses and 118-buses systems;

- The result is compared to many previous methods, which shows the effectiveness of the suggested HCSA-SFO method in dealing with the OPF problem.

The structure of manuscript are given as follows: Section 2 of manuscript presents the OPF problem formulation, while the original CSA and SFO algorithm is presented in Section 3; Furthermore, Section 3.3 also introduces the HCSA-SFO technique and implementing HCSA-SFO for dealing with 
the OPF is applied in detail in Sections 3.1 and 3.2. The calculated results and comparisons to other techniques are shown in Section 4. Conclusions are described in Section 5.

\section{Problem Formulation}

The OPF problem is one of the optimization problems related to the operation of power systems. It is usually used to minimize the objective functions with many controlled variables while satisfying the security constraints of power systems [25]. The OPF problem can be described as follows:

$$
\operatorname{Min} f f(x, u)
$$

Subject to:

- The constraints of equality and inequality.

$$
\begin{aligned}
& \mathrm{g}(\mathrm{x}, \mathrm{u})=0 \\
& \mathrm{~h}(\mathrm{x}, \mathrm{u}) \leq 0
\end{aligned}
$$

where, $f f$ is the goal function which is optimized; $g(x, u)$ and $h(x, u)$ are the constraints of equality and inequality; $x$ is the state variable vector which includes variables of slack bus's active power $P_{\mathrm{G} 1}$, the voltage of load bus $\mathrm{V}_{\mathrm{L}}$, reactive generation power $\mathrm{Q}_{\mathrm{G}}$ and apparent power at branch $\mathrm{S}_{1}$ as shown in Equation (4); $\mathrm{u}$ is the control variable vector which includes variables of active generation power $P_{G}$, generator voltages $V_{G}$, tap ratio of transformer $T$ and shunt compensation capacitor $Q_{c}$ as shown in Equation (5).

$$
\begin{gathered}
x=\left[P_{G 1}, V_{L 1}, \ldots, V_{L N_{L}}, Q_{G 1}, \ldots, Q_{G N_{G}}, S_{l 1}, \ldots, S_{l N_{T L}}\right] \\
u=\left[P_{G 2}, \ldots, P_{G N_{G}}, V_{G 1}, \ldots, V_{G N_{G}}, T_{1}, \ldots, T_{N_{T}}, Q_{c 1}, \ldots, Q_{c N_{C}}\right]
\end{gathered}
$$

where, $\mathrm{N}_{\mathrm{L}}, \mathrm{N}_{\mathrm{G}}, \mathrm{N}_{\mathrm{TL}}, \mathrm{N}_{\mathrm{T}}$ and $\mathrm{N}_{\mathrm{C}}$ are the number of load nodes, generator nodes, transmission lines, tap transformers and the number of VAR compensators, respectively.

\subsection{OPF Objective Functions}

The objectives functions are minimized in the study and include fuel cost, power loss and deviation of voltage.

- Fuel cost:

$$
F_{C}=\sum_{i=1}^{N G} F\left(P_{G i}\right)=\sum_{i=1}^{N G} a_{i}+b_{i} P_{G i}+c_{i} P_{G i}^{2}
$$

- Total real power losses

$$
F_{T L}=\sum_{k=1}^{N_{T L}} g_{k}\left(V_{i}^{2}+V_{j}^{2}-2 V_{i} V_{j} \cos \theta_{i j}\right)
$$

- Voltage deviation

$$
F_{V}=\sum_{i=1}^{N_{L}}\left|V_{L i}-V_{r e f}\right|
$$

where, $a_{i}, b_{i}$ and $c_{i}$ are cost factors of the generator $i ; g_{k}$ is the conductance at $k_{t h}$ line; $V_{i}, V_{j}$ is voltages amplitude of bus $i$ and $j ; \theta_{i j}$ is voltage angle difference between bus $i$ and $j$. 


\subsection{Constraints}

- Constraints of power balance

$$
\begin{aligned}
& P_{G i}-P_{D i}-\left\{V_{i}^{2} G_{i i}+\sum_{\substack{j=1 \\
i \neq j}}^{N_{B}} V_{i} V_{j}\left[G_{i j} \cos \left(\delta_{i}-\delta_{j}\right)+B_{i j} \sin \left(\delta_{i}-\delta_{j}\right)\right]\right\}=0 \\
& Q_{G i}-Q_{D i}-\left\{\begin{array}{l}
\left.-V_{i}^{2} B_{i i}-\sum_{j=1}^{N_{B}} V_{i} V_{j}\left[G_{i j} \sin \left(\delta_{i}-\delta_{j}\right)-B_{i j} \cos \left(\delta_{i}-\delta_{j}\right)\right]\right\}=0 \\
i \neq j
\end{array}\right]=0
\end{aligned}
$$

- The limits of power generation:

$$
\begin{gathered}
P_{G i, \text { min }} \leq P_{G i} \leq P_{G i, \max }, i=1,2, \ldots, N_{G} \\
Q_{G i, \text { min }} \leq Q_{G i} \leq Q_{G i, \max }, i=1,2, \ldots, N_{G}
\end{gathered}
$$

- The limits of generator voltage bus and load voltage bus:

$$
\begin{gathered}
V_{G i, \text { min }} \leq V_{G i} \leq V_{G i, \text { max }}, i=1,2, \ldots, N_{G} \\
V_{L i, \text { min }} \leq V_{L i} \leq V_{L i, \text { max }}, i=1,2, \ldots, N_{L}
\end{gathered}
$$

- The limits of switchable capacitor capacity:

$$
Q_{c i, \min } \leq Q_{c i} \leq Q_{c i, \max }, i=1,2, \ldots, N_{c}
$$

- The limits of transformer tap:

$$
T_{k, \min } \leq T_{k} \leq T_{k \text { max }}, k=1,2, \ldots, N_{T}
$$

- The limits of transmission line:

$$
S_{l} \leq S_{l, \max }, l=1,2, \ldots, N_{\mathrm{TL}}
$$

where, $N_{B}$ is the total number of nodes; $P_{D i}, Q_{D i}$ are active and reactive power of load at bus $i ; G_{i j}, B_{i j}$ are the real and imaginary parts of the admittance between bus $i$ and $j ; \delta_{i}, \delta_{j}$ are the voltage angles at bus $i$ and $j ; P_{G i, m a x}, P_{G i, m i n}$ and $Q_{G i, m a x}, Q_{G i, m i n}$ are the limits of active and reactive capacity outputs of generator $\mathrm{i} ; \mathrm{V}_{\mathrm{Gi}, \max }, \mathrm{V}_{\mathrm{Gi} \text {,min }}$ and $\mathrm{V}_{\mathrm{Li} \text {,max }}, \mathrm{V}_{\mathrm{Li} \text {,min }}$ are the limits of the voltage magnitude of generator $\mathrm{i}$ and load $\mathrm{i}$, respectively; $\mathrm{Q}_{\mathrm{c}, \max }, \mathrm{Q}_{\mathrm{ci}, \min }$ and $\mathrm{T}_{\mathrm{k}, \max }, \mathrm{T}_{\mathrm{k}, \min }$ are the limits of the capacity of switchable capacitor bank and tap changer of transformer $\mathrm{i} ; \mathrm{S}_{1, \max }$ is the maximum capacity of transmission line $\mathrm{i}$.

\section{Implementation of HCSA-SFO for Dealing with the Problem}

\subsection{SFO Method}

The SFO approach is inspired by nature and was proposed by G. F. Gomes, et al. in 2019 [38]. The SFO algorithm simulates the movement of the sunflower toward the sun. Sunflowers' activity is repeated every morning based on their behavior. These sunflowers search for the best orientation to 
the sun and move themselves to best catch the sun's radiation. In the morning, the sunflowers move toward the sun and the opposite orientation at the end of the day. The sunflowers' growing rule is repeated for the next morning. The sunflowers which are close to the sun's direction will collect more heat than those far from the sun's direction; hence they remain still in this region. On the contrary, those which are located in the region far from the sun's direction will take larger steps for moving as close to the sun as possible to the global optimum.

The steps of the SFO algorithm are:

1. Generate the population $X_{i}^{t}$ randomly, $\mathrm{i}=1, \ldots, \mathrm{n}$.

2. The fitness function $f\left(X_{i}^{t}\right)$ of sunflowers is evaluated.

3. Retain the best solutions in the sunflower population $X^{*}$.

4. Modify all sunflowers headed for the best one (called sun) as Equation (18).

$$
\vec{s}_{i}=\frac{X^{*}-X_{i}}{\left\|X^{*}-X_{i}\right\|}, \quad i=1,2 \ldots, n
$$

5. Determine the direction for each sunflower by Equation (19).

$$
d_{i}=\lambda \times P_{i}\left(\left\|X_{i}+X_{i-1}\right\|\right) \times\left\|X_{i}+X_{i-1}\right\|,
$$

In which,

$\lambda$ : Inertial displacement of the sunflower plants.

$\mathrm{p}_{\mathrm{i}}$ : Pollination probability.

$X_{i}, X_{i-1}$ : Current position and nearest neighbor position

6. Examine the highest step of individual as Equation (20).

$$
d_{\max }=\frac{\left\|X_{\max }-X_{\min }\right\|}{2 \times N_{\text {pop }}}
$$

where,

$X_{\min }, X_{\max }$ : The lower and upper limits.

$N_{\text {pop }}$ : the number of populations.

The position of new generated individual (sunflower) is updated using the as Equation (21).

$$
\vec{X}_{i+1}=X_{i}+d_{i} \times \vec{s}_{i}
$$

\subsection{CSA Method}

The CSA method was developed based on the behavior of some cuckoo breeds. The cuckoo leaves her eggs in the bird nests selected at random from other host birds. The cuckoo's egg will be brooded with a host birds' eggs by the host birds. The processing of laying and moving of cuckoos is performed according to the Lévy flight function. There are two crucial search capabilities in the CSA algorithm, global and local search, which are evaluated by a discovery rate. The Lévy flight function with infinite mean and variance is used for global search rather than the random walk technique.

There are three principle rules that are used in CSA:

- A cuckoo lays its one egg into a bird nest which is selected at random from other host birds.

- The best nests will bear to the next generation. 
- A host bird may detect a strange egg by a probability pa $\epsilon[0,1]$. For this situation, the host bird can throw out the cuckoo's egg or leave the nest and find another place for building a new one (with new random solutions).

The CSA maintains a balance between global and the local search random which is controlled by the parameter $\mathrm{Pa} \in[0,1]$. Equations (22) and (23) present the local and global random walks, respectively [36,37]:

$$
\begin{gathered}
X_{i}^{t+1}=X_{i}^{t}+\alpha s \otimes H\left(P_{a}-\varepsilon\right) \otimes\left(X_{j}^{t}-X_{k}^{t}\right) \\
X_{i}^{t+1}=X_{i}^{t}+\alpha L(s, \lambda)
\end{gathered}
$$

where:

$X_{i}, X_{j}$ and $X_{k}$ : Current positions selected randomly

$\alpha>0$ : Scaling coefficient

$X_{i}^{t+1}$ : Position $\mathrm{i}+1$

s: Step size

$\otimes$ : Entry-wise product

$\mathrm{H}$ : Heaviside function

$\varepsilon$ : Random number

$\mathrm{L}(\mathrm{s}, \lambda)$ : Lévy distribution.

The steps of are in Table 1:

Table 1. Cuckoo search algorithm (CSA) pseudocode.

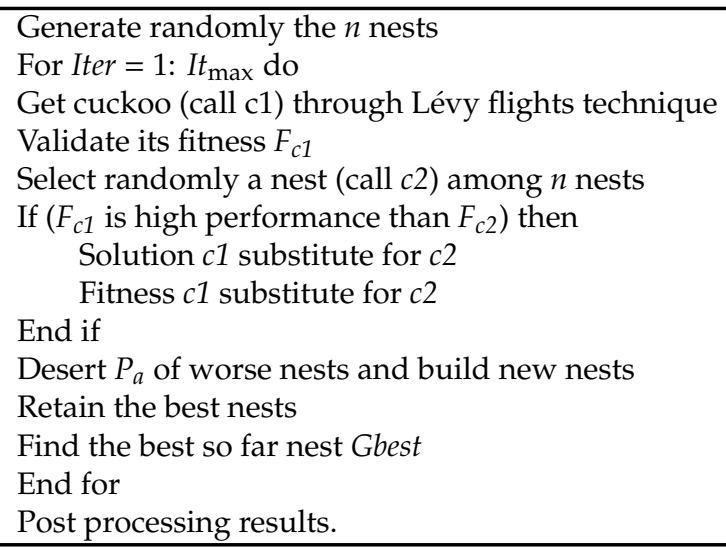

\subsection{Implementation of the Hybrid CSA and SFO Method}

The effective solution of the optimization approaches will be improved with a balance between exploitation and exploration. Exploration is used to ensure finding the global solution, while exploitation is performed to search the best optimal values around current good solutions. So, finding a suitable balance between exploitation and exploration from the combination of the CSA and SFO promises to be an effective technique for dealing with the optimization problem. With that viewpoint, this paper suggests a hybrid CSA and SFO (HCSA-SFO) technique for the OPF problem with several objective functions. The main objective of the suggested technique is to replace Lévy flight function in CSA by using mutation and selection mechanism in the SFO algorithm to avoid the fixed step size in CSA, in order to increase the effective global search and improving the quality of candidate solution. as below:

The steps of the suggested HCSA-SFO technique for dealing with the OPF problem are given

Step 1: Set HCSA-SFO parameters 
Before performing the procedure, it is necessary to set the control parameters of HCSA-SFO, such as the population size $\mathrm{Np}$, mortality rate $\mathrm{m}$, pollination rate $\mathrm{p}$, maximum number of iterations Nmax, probability $\mathrm{Pa} \in[0,1]$.

Step 2: Generate a population of solutions

Each solution in the population is initialized by

$$
\operatorname{Sol}_{i}^{(0)}=\operatorname{Sol}_{i j}^{\min }+\operatorname{rand}_{1} \times\left(\operatorname{Sol}_{i j}^{\max }-\operatorname{Sol}_{i j}^{\min }\right), i=1 \ldots n_{S} ; j=1 \ldots d
$$

where $S o l_{i}$ is the $i$ th solution in population; $S o l_{i j m a x}$ and $S o l_{i j m i n}$ are upper and lower limits of the $j$ th element in candidate solution; $d$ is the problem's dimension and $\operatorname{rand}_{1}$ is the random numbers in $[0,1]$.

Step 3: Evaluate the initial solutions in the population:

The quality of initialized solutions is evaluated by the fitness function Equation (25) via solving the power flow problem. Find the best solution $\left(S_{o l} l_{\text {best }}\right)$ with the corresponding best fitness value $F F_{\text {best }}$.

$$
F F_{i}^{(0)}=F+K_{p}\left(P_{G 1}-P_{G 1}^{\lim }\right)^{2}+K_{q} \sum_{i=1}^{N_{G}}\left(Q_{G i}-Q_{G i}^{\lim }\right)^{2}+K_{v} \sum_{i=1}^{N_{L}}\left(V_{L i}-V_{L i}^{\lim }\right)^{2}+K_{s} \sum_{l=1}^{N_{T L}}\left(S_{l}-S_{l, \max }\right)^{2}
$$

where, $\mathrm{F}$ is the objective function of each case $\left(\mathrm{F}_{\mathrm{C}}, \mathrm{F}_{\mathrm{TL}}, \mathrm{F}_{\mathrm{V}}\right)$ that is defined by Equations (6)-(8).

Set the iteration counter $n=1$.

Step 4: Generate the first new solutions:

Create new solutions by using the mechanism of SFO. The step of each solution towards the best solution is calculated by Equations (18)-(20). The new solution of the population is updated using Equation (21).

Step 5: Evaluate the first new solutions:

Evaluate the quality of the first new solutions $\operatorname{Sol}_{i}^{\text {new(n) }}$ by fitness function Equation (25) via solving the power flow problem. Update the population of the new solutions $S_{i}{ }_{i}^{\text {new }}(n)$ with the corresponding new fitness function value $F F_{i}^{n e w(n)}$. Update the best solution $\left(S_{\text {ol }} l_{\text {best }}\right.$ ) with the corresponding best fitness function value $F F_{d b e s t}$

$$
\operatorname{Sol}_{i}^{\text {new }(n)}= \begin{cases}\text { Sol }_{i}^{(n)} & \text { iffF } F_{i}^{\text {new }(n)} \leq F F_{i}^{(0)} \\ \text { Sol }_{i}^{(0)} & \text { otherwise }\end{cases}
$$

Step 6: Generate a second new solution using fraction (Pa)

The second new solution $\mathrm{Sol}_{i}{ }_{i}^{\text {new (n) }}$ is created with probability Pa of CSA. The new solutions of the population are updated using Equation (22).

Step 7: Evaluate the new second solutions:

The quality of the new second solutions is evaluated by fitness function Equation (25) via solving the power flow problem. Update the population of the new second solution $\operatorname{Sol}_{i}{ }_{i}^{\text {new }}(n)$ with the corresponding new second fitness function value $F F_{i}^{\prime \text { new }(n)}$. Update the best solution $\left(S_{\text {ol }} l_{\text {ibest }}\right)$ with the corresponding best fitness function value $F F_{\text {ibest }}$

$$
\operatorname{Sol}_{i}^{\text {new }(n)}= \begin{cases}\operatorname{Sol}_{i}^{(n)} & \text { if } F F_{i}^{\text {new }(n)} \leq F F_{i}^{(0)} \\ \operatorname{Sol}_{i}^{(0)} & \text { otherwise }\end{cases}
$$


Step 8: Check the sopping condition:

If $n<$ Nmax, $n=n+1$, the searching process will return to Step 4 for finding the optimal solution. Otherwise, the searching process will stop.

\section{Simulation Results}

\subsection{The IEEE 30-Bus Test System}

The system includes six generators, 24 load buses and 41 lines, as in Figure 1. The generator buses are set up voltage value within [0.95-1.1 p.u], while the voltages at load buses are limited [0.95-1.05 p.u]. The regulating transformers have voltage tap settings within [0.9-1.1 p.u]. The rating of shunt capacitors is in the range of [0-5 MVAR]. The system, generator data and operating conditions for the IEEE 30-bus test system are given in Table 2 and in [25,39].

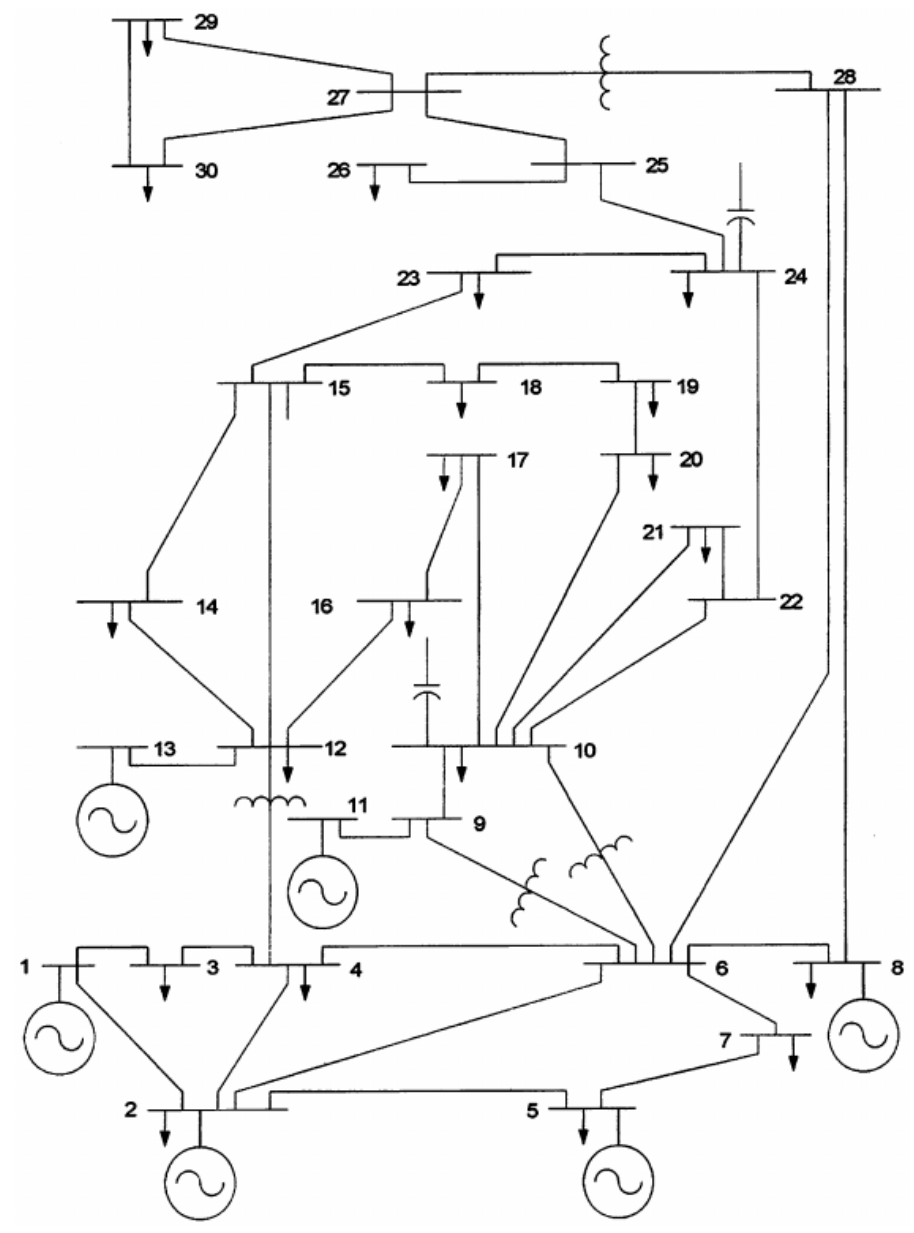

Figure 1. The 30-bus system.

Table 2. Generator data of the 30-bus system.

\begin{tabular}{cccc}
\hline Bus No & ai $\mathbf{( \$ / h )}$ & bi $\mathbf{( \$ \mathbf { M W h } )}$ & ci $\mathbf{( \$ \mathbf { M W 2 h } )}$ \\
\hline 1 & 0.00 & 2 & 0.00375 \\
\hline 2 & 0.00 & 1.75 & 0.01750 \\
\hline 5 & 0.00 & 1.00 & 0.06250 \\
\hline 8 & 0.00 & 3.25 & 0.00834 \\
\hline 11 & 0.00 & 3.00 & 0.02500 \\
\hline 13 & 0.00 & 3.00 & 0.02500 \\
\hline
\end{tabular}


Table 3 presents obtained optimal values using CSA and HCSA-SFO for cases 1-3, consisting of fuel cost, power loss and voltage deviations. In addition, these control parameters are also presented in this table. From this table, the total generator cost obtained is $799.118(\$ / \mathrm{h})$ using the HCSA-SFO technique, while the total generator cost using the CSA approach is $799.129(\$ / \mathrm{h})$ for case 1 . For case 1 , the total generator cost of the CSA approach approximates that of the HCSA-SFO approach; however, the run time of the suggested HCSA-SFO technique is shorter than that of the CSA approach for all of simulation cases. Wherein, the run time of HCSA-SFO is 9.0261, 7.0549 and 7.3082 s, which are less than those of CSA for solving the problem in case 1, case 2 and case 3, respectively. The convergence curve of the total fuel cost objective function is demonstrated in Figure 2. From this figure, convergence ability to the optimal value of the HCSA-SFO algorithm is better than CSA in terms of optimal value. 
Table 3. The results of CSA and hybrid cuckoo search algorithm and sunflower optimization (HCSA-SFO) for the 30-bus system with case 1-3.

\begin{tabular}{|c|c|c|c|c|c|c|c|c|c|}
\hline \multirow[t]{2}{*}{ Control Parameters (U) } & \multirow[t]{2}{*}{ Initial State } & \multicolumn{2}{|c|}{ Limits } & \multicolumn{2}{|c|}{ Case 1: Total Generator Cost } & \multicolumn{2}{|c|}{ Case 2: Voltage Profile } & \multicolumn{2}{|c|}{$\begin{array}{l}\text { Case 3: Total Active Power } \\
\text { Loss }\end{array}$} \\
\hline & & Min & $\operatorname{Max}$ & CSA & HCSA-SFO & CSA & HCSA-SFO & CSA & HCSA-SFO \\
\hline P1(MW) & 99.221 & 50 & 200 & 177.219 & 177.148 & 129.717 & 117.597 & 51.2794 & 51.2795 \\
\hline P2(MW) & 80.0 & 20 & 80 & 48.6847 & 48.7207 & 60.2810 & 48.1157 & 79.9966 & 79.9964 \\
\hline $\mathrm{P} 5(\mathrm{MW})$ & 50.00 & 15 & 50 & 21.2218 & 21.3127 & 39.4447 & 50.0000 & 50.0000 & 50.0000 \\
\hline P8(MW) & 20.0 & 10 & 35 & 21.1297 & 20.9526 & 18.4269 & 33.2425 & 34.9992 & 34.9995 \\
\hline P11(MW) & 20.0 & 10 & 30 & 11.7964 & 11.9111 & 19.3629 & 23.0321 & 30.0000 & 30.0000 \\
\hline P13(MW) & 20.0 & 12 & 40 & 12.0019 & 12.0000 & 23.3748 & 17.2583 & 40.0000 & 39.9995 \\
\hline V1 (p.u) & 1.0500 & 0.95 & 1.1 & 1.1000 & 1.1000 & 1.0144 & 1.0075 & 1.1000 & 1.1000 \\
\hline V2 (p.u) & 1.0400 & 0.95 & 1.1 & 1.0879 & 1.0878 & 1.0073 & 1.0000 & 1.0977 & 1.0979 \\
\hline V5 (p.u) & 1.0100 & 0.95 & 1.1 & 1.0617 & 1.0615 & 1.0189 & 1.0156 & 1.0798 & 1.0804 \\
\hline V8 (p.u) & 1.0100 & 0.95 & 1.1 & 1.0704 & 1.0693 & 1.0092 & 1.0142 & 1.0875 & 1.0878 \\
\hline V11(p.u) & 1.0500 & 0.95 & 1.1 & 1.0998 & 1.1000 & 1.0179 & 1.0377 & 1.1000 & 1.1000 \\
\hline V13(p.u) & 1.0500 & 0.95 & 1.1 & 1.0999 & 1.1000 & 1.0132 & 1.0176 & 1.1000 & 1.0998 \\
\hline T11 & 1.0780 & 0.9 & 1.1 & 1.0485 & 1.0596 & 1.0315 & 1.0531 & 1.0681 & 1.0650 \\
\hline $\mathrm{T} 12$ & 1.0690 & 0.9 & 1.1 & 0.9220 & 0.9000 & 0.9009 & 0.9013 & 0.9001 & 0.9000 \\
\hline T15 & 1.0320 & 0.9 & 1.1 & 1.0023 & 0.9929 & 0.9962 & 0.9911 & 0.9854 & 0.9844 \\
\hline T36 & 1.0680 & 0.9 & 1.1 & 0.9723 & 0.9687 & 0.9579 & 0.9733 & 0.9754 & 0.9748 \\
\hline QC10 (MVAR) & 0 & 0 & 5 & 5.0000 & 5.0000 & 5.0000 & 2.8273 & 4.9999 & 4.9688 \\
\hline QC12 (MVAR) & 0 & 0 & 5 & 4.9779 & 5.0000 & 4.5504 & 1.3736 & 4.9967 & 4.9994 \\
\hline QC15 (MVAR) & 0 & 0 & 5 & 4.8721 & 5.0000 & 5.0000 & 4.9758 & 4.9991 & 4.9935 \\
\hline QC17 (MVAR) & 0 & 0 & 5 & 4.9764 & 5.0000 & 1.1845 & 1.1102 & 4.9897 & 4.9998 \\
\hline QC20 (MVAR) & 0 & 0 & 5 & 4.2118 & 4.4761 & 5.0000 & 4.9997 & 3.8542 & 4.2219 \\
\hline QC21 (MVAR) & 0 & 0 & 5 & 5.0000 & 5.0000 & 4.4159 & 4.7205 & 4.9989 & 5.0000 \\
\hline QC23 (MVAR) & 0 & 0 & 5 & 3.0770 & 2.8877 & 4.6104 & 4.9371 & 2.7502 & 2.8132 \\
\hline QC24 (MVAR) & 0 & 0 & 5 & 4.9494 & 5.0000 & 4.9751 & 5.0000 & 5.0000 & 4.9994 \\
\hline QC29 (MVAR) & 0 & 0 & 5 & 2.5377 & 2.6939 & 1.9721 & 4.0838 & 2.6171 & 2.5271 \\
\hline Total cost $(\$ / \mathrm{h})$ & 830.02 & - & - & 799.129 & 799.118 & 842.270 & 876.855 & 967.117 & 967.115 \\
\hline PLoss (MW) & 5.8486 & - & - & 8.6536 & 8.6456 & 7.2076 & 5.8463 & 2.8752 & 2.8748 \\
\hline$\sum$ Voltage deviation & 1.1665 & - & - & 1.7622 & 1.8259 & 0.0961 & 0.0945 & 2.0369 & 2.0554 \\
\hline Run time (s) & - & - & - & 86.8238 & 77.7977 & 82.1847 & 75.1298 & 79.9934 & 72.6852 \\
\hline
\end{tabular}




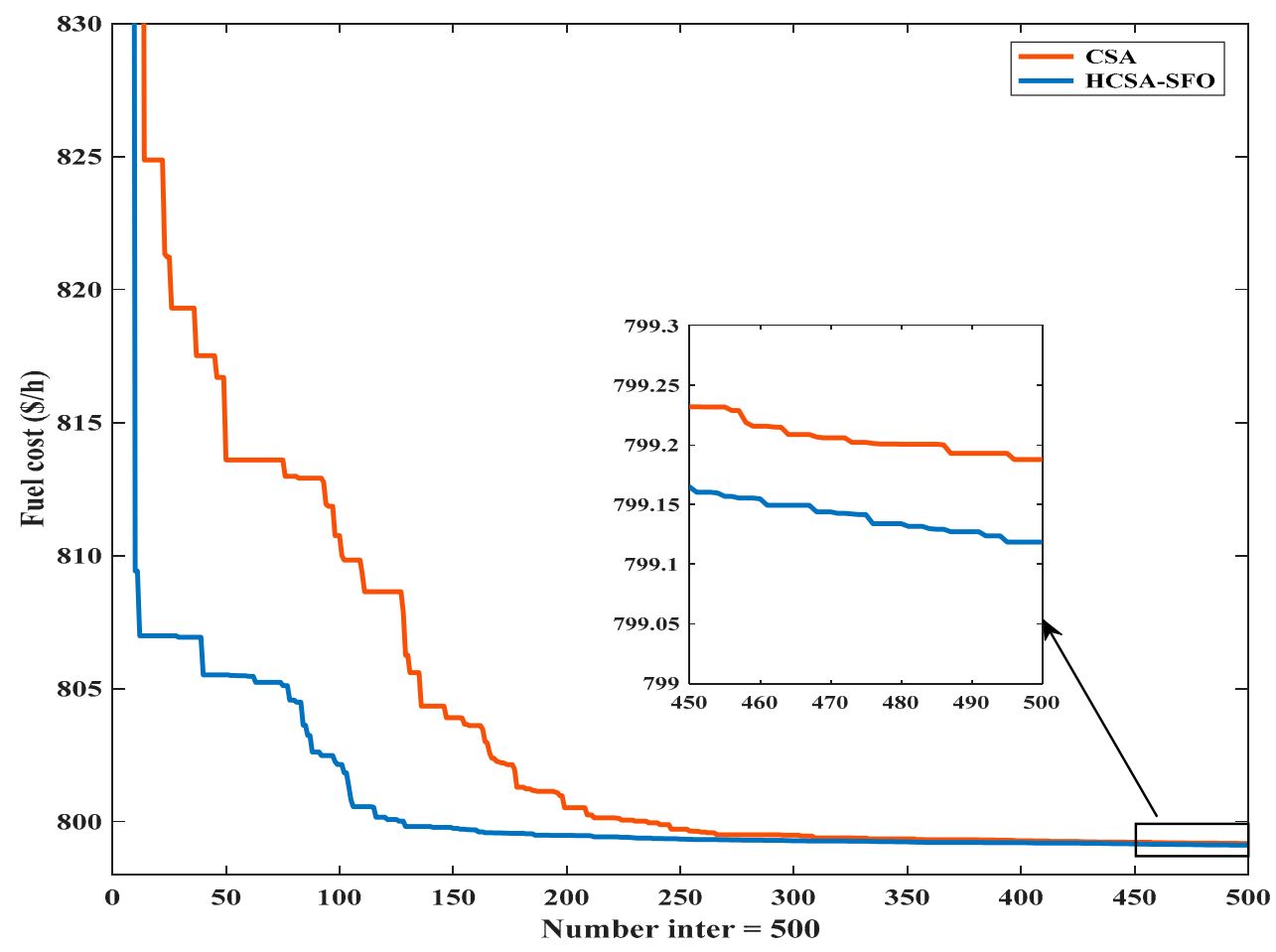

Figure 2. Convergence curves of the CSA and HCSA-SFO for case 1.

In order to evaluate the effectiveness of the suggested HCSA-SFO technique in dealing with the OPF problem, simulations results of the HCSA-SFO technique is compared with many other approaches as demonstrated in Table 4. For case 1, it can be seen from the Table 4, total fuel cost obtained by HCSA-SFO is $799.11(\$ / \mathrm{h})$, which is better than many other methods in the literature. This is the demonstration of the robustness of the hybrid HCSA-SFO technique in dealing with OPF.

Table 4. Compared results of HCSA-SFO and other methods for cases 1, 2 and 3.

\begin{tabular}{cccc}
\hline \multirow{2}{*}{ Method } & Case 1 & Case 2 & Case 3 \\
\cline { 2 - 4 } & Total Generator Cost & Voltage Profile & Total Active Power Loss \\
\hline Gradient method [17] & 804.853 & NR & 10.486 \\
\hline DE-OPF [35] & 802.394 & NR & 9.466 \\
\hline MDE-OPF [35] & 802.375 & NR & 9.459 \\
\hline MSFLA [34] & 802.287 & NR & 9.6991 \\
\hline IGA [16] & 800.805 & NR & NR \\
\hline ABC [15] & 800.66 & 0.1381 & 3.1078 \\
\hline GSA [9] & 798.675143 & NR & NR \\
\hline SCA [25] & 800.1018 & 0.1082 & 2.9425 \\
\hline Hybrid PSO-GSA [19] & 800.49859 & 0.12674 & 9.0339 \\
\hline Jaya [18] & 800.4794 & 0.1243 & 3.1035 \\
\hline EGA-DQLF [27] & 799.56 & 0.111 & 3.2008 \\
\hline MSCA [25] & 799.31 & 0.1031 & 2.9334 \\
\hline SPEA [24] & $\mathrm{NR}$ & 0.1247 & NR \\
\hline HS [21] & $\mathrm{NR}$ & 0.1006 & 2.9678 \\
\hline BBO [17] & $\mathrm{NR}$ & 0.09803 & NR \\
\hline CSA & 799.1292 & 0.0961 & 2.8752 \\
\hline HCSA-SFO proposed & 799.1185 & 0.0945 & 2.8748 \\
\hline
\end{tabular}


The simulation results of the HCSA-SFO technique compared with many other approaches for case 2 is also shown in Table 4. As observed from Table 4, the voltage deviation of the suggested HCSA-SFO technique is better than those of many other methods. Moreover, the voltage deviation obtained by HCSA-SFO is $0.0945 \mathrm{pu}$, which is also better than that of CSA as shown in Table 4 .

For case 3, the total active power loss achieved using HCSA-SFO is 2.8748 (MW), while the total active power loss reduces to 2.8752 (MW) using CSA as shown in Table 4. From Table 4, it can be observed that the total power loss of the suggested HCSA-SFO technique obtains a better minimum value compared with other approaches. Besides, the results of fuel cost, voltage deviation and active power loss using CSA and HCSA-SFO also are given in Figures 3-5. From the figures, the results of HCSA-SFO are better than those of CSA for all three cases. In addition, the statistical results of HCSA-SFO and CSA in Table 5 show that HCSA-SFO outperforms CSA in terms of the best, average and the worst fitness values as well as the standard deviation. The analytical results show that HCSA-SFO is also an effective method to find an optimized solution with fast convergence ability.

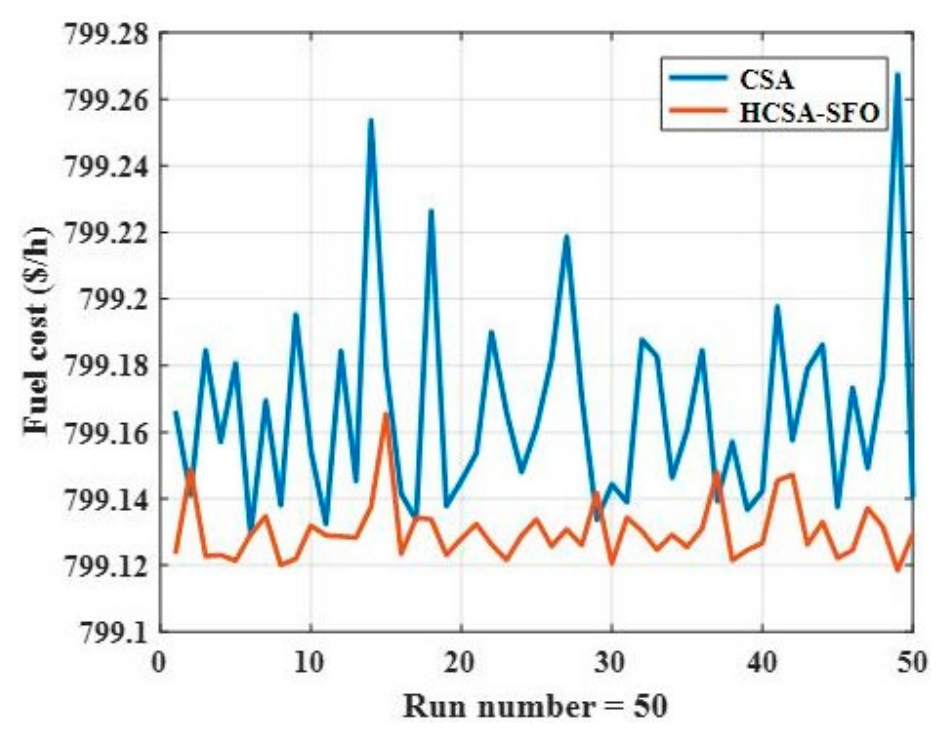

Figure 3. Comparison of fuel cost of the CSA and HCSA-SFO for case 1.

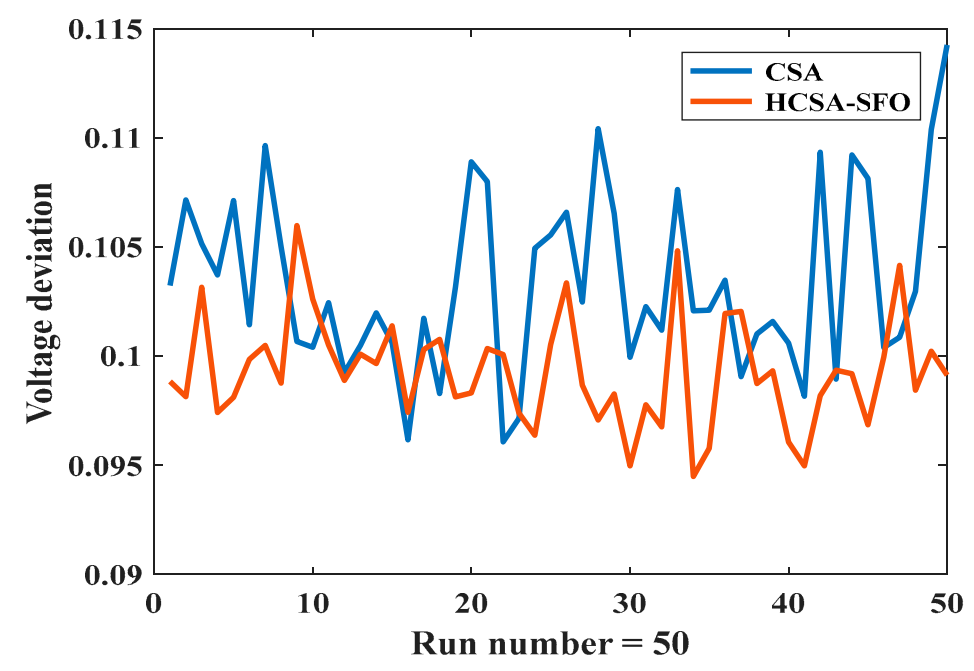

Figure 4. Comparison of voltage deviation of the CSA and HCSA-SFO for case 2. 


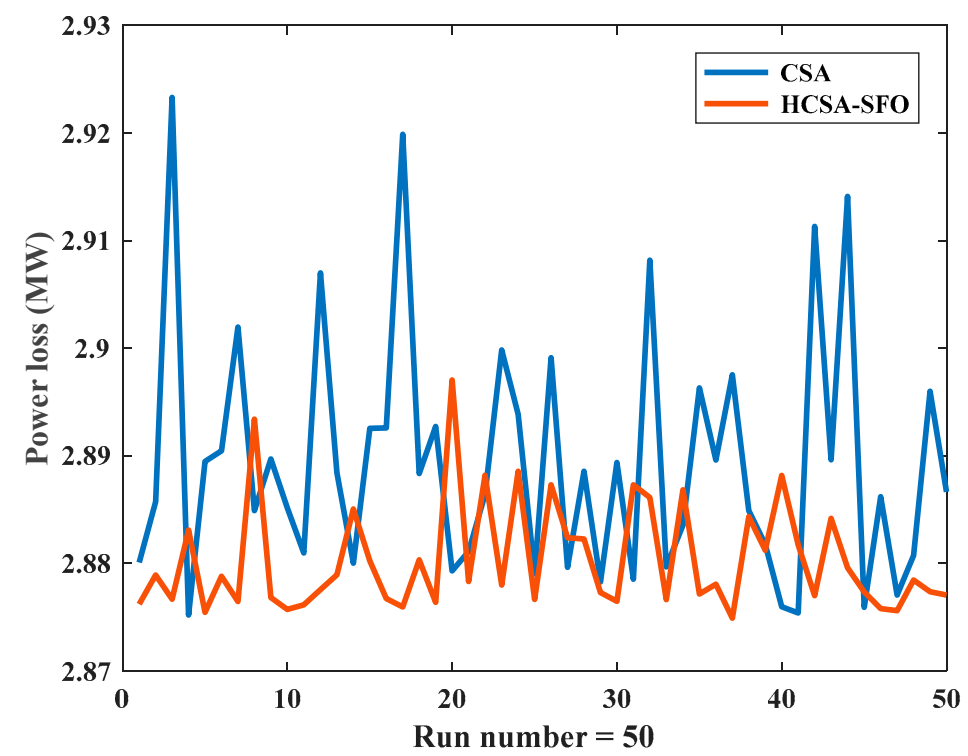

Figure 5. Comparison of active power loss of the CSA and HCSA-SFO for case 3.

Table 5. The statistical results of HCSA-SFO and CSA for case 1, 2 and 3.

\begin{tabular}{ccccccc}
\hline Item & \multicolumn{2}{c}{ Case 1 } & \multicolumn{2}{c}{ Case 2 } & \multicolumn{2}{c}{ Case 3 } \\
\hline Method & CSA & HCSA-SFO & CSA & HCSA-SFO & CSA & HCSA-SFO \\
\hline Best fitness & 799.1292 & 799.1185 & 0.0961 & 0.0945 & 2.8752 & 2.8748 \\
\hline Average fitness & 799.1661 & 799.1301 & 0.1034 & 0.0993 & 2.8894 & 2.8803 \\
\hline Worst fitness & 799.2675 & 799.1655 & 0.1143 & 0.1060 & 2.9233 & 2.8970 \\
\hline Standard deviation & 0.0302 & 0.0089 & 0.0041 & 0.0025 & 0.0116 & 0.0051 \\
\hline
\end{tabular}

\subsection{The IEEE 118-Bus Test System}

The larger power system with the standard IEEE 118-bus is used to test the robustness of HCSA-SFO for dealing with the OPF problem. Parameters of the 118-bus system are given in [25,39]. The 118-bus system includes 118 buses, which are 99 load buses, 54 thermal units, 186 branches, 9 transformers and 12 reactive compensations with size within (0-30) MVAr each. The system is considered as a large-scale OPF problem which is usually used to test the robustness of many other algorithms.

The optimal value of objective function and control optimal parameters for the IEEE 118-bus system using CSA and suggested HCSA-SFO is presented in Table 6. From Table 6, the total generator cost achieved is $129,619.848(\$ / \mathrm{h})$ using HCSA-SFO, while the total generator cost achieved by CSA is $129,847.86(\$ / \mathrm{h})$. Moreover, Table 6 also shows that the run time to the obtained optimal value of the suggested HCSA-SFO method is $234.2190 \mathrm{~s}$, which is $44.2609 \mathrm{~s}$ less than of CSA. Besides, the variation of the total generator cost is also presented in Figure 6. From this figure, the convergence ability of the HCSA-SFO technique for the OPF problem with large scale systems can be demonetized. For additional effective confirmation, the results of HCSA-SFO are also compared with many other approaches, as shown in Table 7. From Table 7, HCSA-SFO achieved the solution better than many other methods. Table 8 presents the values of optimal objective functions for cases 2 and 3 obtained by HCSA-SFO compared to CSA. As observed, the suggested HCSA-SFO achieved better optimal results than the CSA algorithm. The voltage deviation decreases to 0.3836 in case 2 and the power loss of 11.2784 MW in case 3 using HCSA-SFO, while the voltage deviation is 0.6117 in case 2 and the power loss $21.3664 \mathrm{MW}$ in case 3 using CSA. 
Table 6. The solution of optimal power flower (OPF) achieved for IEEE 118-bus system with case 1.

\begin{tabular}{|c|c|c|c|c|c|c|c|c|c|}
\hline & $\begin{array}{l}\text { Control } \\
\text { Parameter }\end{array}$ & CSA & HCSA-SFO & $\begin{array}{l}\text { Control } \\
\text { Parameter }\end{array}$ & CSA & HCSA-SFO & $\begin{array}{l}\text { Control } \\
\text { Parameter }\end{array}$ & CSA & HCSA-SFO \\
\hline 4 & PG01 (MW) & 26.8831 & 25.7191 & V01 (p.u.) & 1.0496 & 1.06 & T5_8 (p.u.) & 0.9819 & 0.9588 \\
\hline 6 & PG04 (MW) & 0.0011 & 0 & V04 (p.u.) & 1.0196 & 1.0583 & T25_26 (p.u.) & 1.0544 & 1.0599 \\
\hline 8 & PG06 (MW) & 0.0036 & 0.0006 & V06 (p.u.) & 1.0107 & 1.0511 & T17_30 (p.u.) & 0.994 & 0.9792 \\
\hline 10 & PG08 (MW) & 0 & 0 & V08 (p.u.) & 1.0248 & 1.0343 & T37_38 (p.u.) & 0.9994 & 0.9704 \\
\hline 12 & PG010 (MW) & 398.447 & 401.4037 & V10 (p.u.) & 1.0499 & 1.0599 & T59_63 (p.u.) & 1.0144 & 0.9855 \\
\hline 15 & PG012 (MW) & 85.7506 & 85.6885 & V12 (p.u.) & 1.0065 & 1.0486 & T61_64 (p.u.) & 1.0234 & 0.9992 \\
\hline 18 & PG015 (MW) & 22.1625 & 20.3813 & V15 (p.u.) & 1.0007 & 1.0486 & T65_66 (p.u.) & 0.9771 & 0.9853 \\
\hline 19 & PG018 (MW) & 12.943 & 12.9764 & V18 (p.u.) & 1.0024 & 1.0506 & T68_69 (p.u.) & 0.9 & 0.9548 \\
\hline 24 & PG019 (MW) & 22.3069 & 21.4271 & V19 (p.u.) & 0.9985 & 1.0481 & T80_81 (p.u.) & 0.9985 & 0.9888 \\
\hline 25 & PG24 (MW) & 0.0005 & 0 & V24 (p.u.) & 1.0111 & 1.0501 & QC34 (MVAR) & 4.9211 & 0.034 \\
\hline 26 & PG25 (MW) & 193.8773 & 194.4536 & V25 (p.u.) & 1.0398 & 1.06 & QC44 (MVAR) & 3.0739 & 4.1145 \\
\hline 27 & PG26 (MW) & 280.7126 & 280.6595 & V26 (p.u.) & 1.05 & 1.06 & QC45 (MVAR) & 27.4402 & 19.3306 \\
\hline 31 & PG27 (MW) & 10.114 & 11.1432 & V27 (p.u.) & 0.9974 & 1.0455 & QC46 (MVAR) & 2.3706 & 0 \\
\hline 32 & PG31 (MW) & 7.3274 & 7.2506 & V31 (p.u.) & 0.9924 & 1.0411 & QC48 (MVAR) & 2.0481 & 7.637 \\
\hline 34 & PG32 (MW) & 17.6087 & 15.656 & V32 (p.u.) & 0.9969 & 1.0446 & QC74 (MVAR) & 24.7779 & 30 \\
\hline 36 & PG34 (MW) & 5.2681 & 5.7499 & V34 (p.u.) & 1.0015 & 1.0566 & QC79 (MVAR) & 29.722 & 30 \\
\hline 40 & PG36 (MW) & 7.9528 & 0 & V36 (p.u.) & 0.999 & 1.0547 & QC82 (MVAR) & 20.7679 & 29.9971 \\
\hline 42 & PG40 (MW) & 55.5105 & 49.6176 & V40 (p.u.) & 0.9899 & 1.0446 & QC83 (MVAR) & 30 & 9.8588 \\
\hline 46 & PG42 (MW) & 39.0042 & 41.3484 & V42 (p.u.) & 0.9916 & 1.0445 & $\begin{array}{l}\text { QC105 } \\
\text { MVAR) }\end{array}$ & 21.1656 & 30 \\
\hline 49 & PG46 (MW) & 19.1381 & 19.061 & V46 (p.u.) & 0.9961 & 1.0447 & $\begin{array}{c}\text { QC107 } \\
\text { (MVAR) }\end{array}$ & 2.1189 & 0.0008 \\
\hline
\end{tabular}


Table 6. Cont

\begin{tabular}{|c|c|c|c|c|c|c|c|c|c|}
\hline & $\begin{array}{l}\text { Control } \\
\text { Parameter }\end{array}$ & CSA & HCSA-SFO & $\begin{array}{l}\text { Control } \\
\text { Parameter }\end{array}$ & CSA & HCSA-SFO & $\begin{array}{l}\text { Control } \\
\text { Parameter }\end{array}$ & CSA & HCSA-SFO \\
\hline 54 & PG49 (MW) & 193.6385 & 193.8593 & V49 (p.u.) & 1.0136 & 1.0577 & $\begin{array}{c}\text { QC110 } \\
\text { (MVAR) }\end{array}$ & 29.3622 & 25.541 \\
\hline 55 & PG54 (MW) & 49.7253 & 49.4907 & V54 (p.u.) & 0.9923 & 1.0395 & Fuel cost $(\$ / h)$ & $129,847.9$ & $129,619.8$ \\
\hline 56 & PG55 (MW) & 35.8876 & 31.7237 & V55 (p.u.) & 0.9905 & 1.0395 & Plosses (MW) & 81.0879 & 76.8078 \\
\hline 59 & PG56 (MW) & 37.6324 & 32.0909 & V56 (p.u.) & 0.9906 & 1.0392 & $\begin{array}{l}\sum \text { Voltage } \\
\text { deviation }\end{array}$ & 1.7266 & 2.6842 \\
\hline 61 & PG59 (MW) & 148.637 & 149.6631 & V59 (p.u.) & 0.9927 & 1.0572 & Run time (s) & 278.4798 & 234.219 \\
\hline 62 & PG61 (MW) & 147.0241 & 148.5939 & V61 (p.u.) & 1.0039 & 1.06 & & & \\
\hline 65 & PG62 (MW) & 0.0019 & 0 & V62 (p.u.) & 1.0023 & 1.0559 & & & \\
\hline 66 & PG65 (MW) & 351.1325 & 353.3149 & V65 (p.u.) & 1.0281 & 1.06 & & & \\
\hline 69 & PG66 (MW) & 348.2007 & 350.0869 & V66 (p.u.) & 1.0239 & 1.06 & & & \\
\hline 70 & PG69 (MW) & 454.8334 & 455.0162 & V69 (p.u.) & 1.0309 & 1.06 & & & \\
\hline 72 & PG70 (MW) & 0.0002 & 0 & V70 (p.u.) & 0.9968 & 1.0369 & & & \\
\hline 73 & PG72 (MW) & 0.0112 & 0 & V72 (p.u.) & 1 & 1.0407 & & & \\
\hline 74 & PG73 (MW) & 1.0773 & 0 & V73 (p.u.) & 0.9975 & 1.0365 & & & \\
\hline 76 & PG74 (MW) & 0.003 & 17.4254 & V74 (p.u.) & 0.9809 & 1.0277 & & & \\
\hline 77 & PG76 (MW) & 28.817 & 23.2027 & V76 (p.u.) & 0.969 & 1.0122 & & & \\
\hline 80 & PG77 (MW) & 0.0001 & 0 & V77 (p.u.) & 1.0015 & 1.0448 & & & \\
\hline 82 & PG80 (MW) & 429.1381 & 431.9109 & V80 (p.u.) & 1.015 & 1.0584 & & & \\
\hline 85 & PG85 (MW) & 0.001 & 0 & V85 (p.u.) & 1.0108 & 1.0507 & & & \\
\hline 87 & PG87 (MW) & 3.7636 & 3.6263 & V87 (p.u.) & 1.0072 & 1.0537 & & & \\
\hline 89 & PG89 (MW) & 498.3809 & 502.6848 & V89 (p.u.) & 1.0248 & 1.06 & & & \\
\hline
\end{tabular}


Table 6. Cont

\begin{tabular}{|c|c|c|c|c|c|c|c|c|c|}
\hline & $\begin{array}{c}\text { Control } \\
\text { Parameter }\end{array}$ & CSA & HCSA-SFO & $\begin{array}{c}\text { Control } \\
\text { Parameter }\end{array}$ & CSA & HCSA-SFO & $\begin{array}{c}\text { Control } \\
\text { Parameter }\end{array}$ & CSA & HCSA-SFO \\
\hline 90 & PG90 (MW) & 0.0293 & 0 & V90 (p.u.) & 0.9967 & 1.0407 & & & \\
\hline 91 & PG91 (MW) & 0.0137 & 0 & V91 (p.u.) & 0.9967 & 1.0435 & & & \\
\hline 92 & PG92 (MW) & 0.0006 & 0 & V92 (p.u.) & 1.0056 & 1.0488 & & & \\
\hline 99 & PG99 (MW) & 0.0008 & 0 & V99 (p.u.) & 1.001 & 1.0509 & & & \\
\hline 100 & PG100 (MW) & 230.6961 & 231.4663 & V100 (p.u.) & 1.0077 & 1.0548 & & & \\
\hline 103 & PG103 (MW) & 38.1507 & 38.2706 & V103 (p.u.) & 1.0033 & 1.0467 & & & \\
\hline 104 & PG104 (MW) & 0.0086 & 0.0003 & V104 (p.u.) & 0.9938 & 1.0372 & & & \\
\hline 105 & PG105 (MW) & 7.8782 & 5.5612 & V105 (p.u.) & 0.9923 & 1.0345 & & & \\
\hline 107 & PG107 (MW) & 32.89 & 29.3361 & V107 (p.u.) & 0.9853 & 1.0284 & & & \\
\hline 110 & PG110 (MW) & 12.0952 & 7.1166 & V110 (p.u.) & 0.998 & 1.0347 & & & \\
\hline 111 & PG111 (MW) & 35.1675 & 35.2286 & V111 (p.u.) & 1.0063 & 1.0422 & & & \\
\hline 112 & PG112 (MW) & 33.2392 & 36.6019 & V112 (p.u.) & 0.99 & 1.0271 & & & \\
\hline 113 & PG113 (MW) & 0.0001 & 0 & V113 (p.u.) & 1.0099 & 1.056 & & & \\
\hline 116 & PG116 (MW) & 0 & 0 & V116 (p.u.) & 1.0249 & 1.06 & & & \\
\hline
\end{tabular}




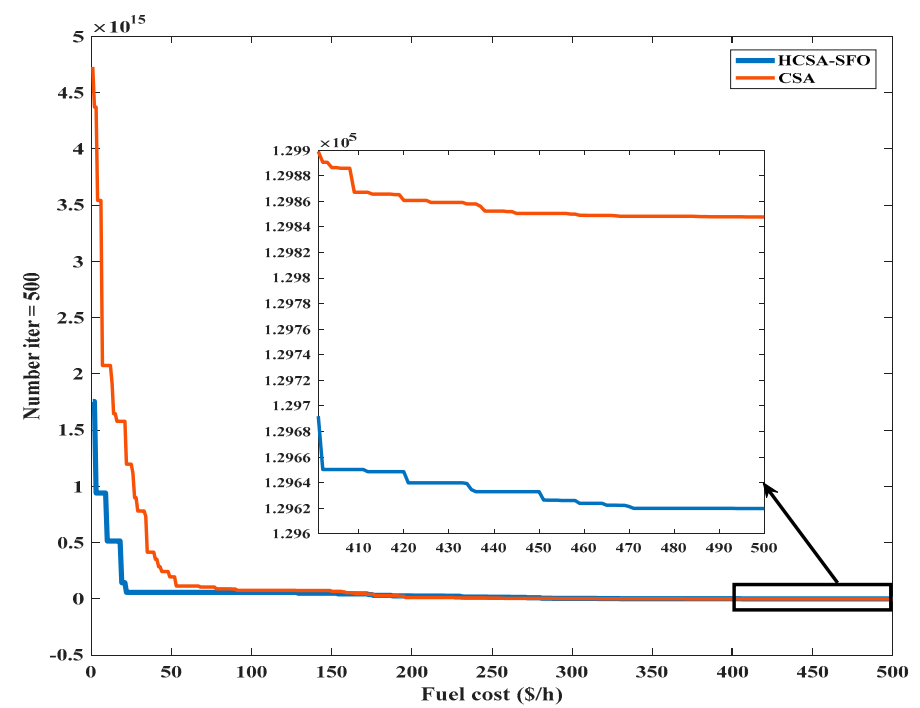

Figure 6. Convergence characteristics of the HCSA-SFO algorithm of IEEE 118 for case 1.

Table 7. Comparison of the results achieved for IEEE 118-bus system with case 1.

\begin{tabular}{cc}
\hline Approach & Total Generator Cost (\$/h) \\
\hline DE [20] & $142,751.1178$ \\
\hline BSO [33] & $135,333.5$ \\
\hline BBO [20] & $135,272.1959$ \\
\hline ECBO [20] & $135,172.266$ \\
\hline ABC [20] & $135,145.1889$ \\
\hline Improved ICBO [20] & $135,121.570$ \\
\hline CBO [20] & $135,072.999$ \\
\hline GWO [7] & $129,720.000$ \\
\hline BBO [17] & $129,686.000$ \\
\hline TLBO [22] & $129,682.844$ \\
\hline SCA [25] & $129,622.650$ \\
\hline MSCA [25] & $129,620.220$ \\
\hline CSA proposed & $129,847.86$ \\
\hline HCSA-SFO proposed & $129,619.848$ \\
\hline
\end{tabular}

Table 8. The results for IEEE 118 bus system with case 1 , case 2 and case 3.

\begin{tabular}{cccc}
\hline \multirow{2}{*}{ Approach Proposed } & Case $\mathbf{1}$ & Case 2 & Case 3 \\
\cline { 2 - 4 } & Generator Cost $\mathbf{( \$ / h )}$ & Voltage Deviation & Total Power Loss (MW) \\
\hline CSA & $129,847.86$ & 0.6117 & 21.3664 \\
\hline HCSA-SFO & $129,619.848$ & 0.3836 & 11.2784 \\
\hline
\end{tabular}

\section{Conclusions}

In the next years, OPF problems will still be one of the important issues of power system operation, especially in the electricity market. Many research teams still continue developing other methods to enhance the performance solution of the OPF problem. This is a nonlinear issue with many control parameters that requires an effective technique in dealing with it. A newly robust hybrid technique, which is successfully applied for dealing with OPF for large-scale systems, is presented in this paper. In order to evaluate the ability to find an optimal solution of the suggested technique, the hybrid HCSA-SFO technique is compared with CSA and many other approaches. The simulation results are 
tested and evaluated for the IEEE 30- and IEEE 118-bus system with the objective function of minimizing generator costs, power loss and voltage deviation. For both of the testing systems, HCSA-SFO reaches better solutions and faster convergence than CSA for all of cases of the objective functions in each independent run as well as in 50 runs. In comparison with other methods, the proposed HCSA-SFO method outperforms other methods. The simulation results achieved show that HCSA-SFO can be a potential approach for dealing with large-scale OPF problems or the OPF problems considering to distributed generation sources and FACTS devices.

Author Contributions: Conceptualization, T.L.D.; methodology, N.A.N.; software, N.A.N.; validation, T.T.N.; formal analysis, T.L.D. and T.T.N.; writing-original draft preparation, T.L.D.; writing-review and editing, T.T.N., T.L.D. and N.A.N.; visualization, T.T.N. All authors have read and agreed to the published version of the manuscript.

Funding: This research received no external funding.

Conflicts of Interest: The authors declare no conflict of interest.

\section{References}

1. Monoh, J.A.; El-Hawary, M.E.; Adapa, R. A review of selected optimal power flow literature to 1993 Part II: Newton, linear programming and Interior Point Methods. IEEE Trans. Power Syst. 1999, 14, $105-111$. [CrossRef]

2. Alsac, O.; Scott, B. Optimal load flow with steady state security. IEEE Trans. Power Appar. Syst. 1974, 93, 745-751. [CrossRef]

3. Alsac, O.; Bright, J.; Prais, M.; Stott, B. Further developments in LP-based optimal power flow. IEEE Trans. Power Syst. 1990, 5, 697-711. [CrossRef]

4. Burchett, R.C.; Happ, H.H.; Vierath, D.R. Quadratically convergent optimal power flow. IEEE Trans. Power Appar. Syst. 1984, 103, 3267-3276. [CrossRef]

5. Sun, D.I.; Ashley, B.; Brewer, B.; Hughes, A.; Tinney, W.F. Optimal power flow by Newton approach. IEEE Trans. Power Appar. Syst. 1984, 103, 2864-2880. [CrossRef]

6. Ongsakul, W.; Tantimaporn, T. Optimal power flow by improved evolutionary programming. Electr. Power Compon. Syst. 2006, 34, 79-95. [CrossRef]

7. El-Fergany, A.A.; Hasanien, H.M. Single and multi-objective optimal power flow using grey wolf optimizer and differential evolution algorithms. Electr. Power Compon. Syst. 2015, 43, 1548-1559. [CrossRef]

8. Hazra, J.; Sinha, A.K. A multi-objective optimal power flow using particle swarm optimization. Eur. Trans. Electr. Power 2011, 21, 1028-1045. [CrossRef]

9. Duman, S.; Güvenç, U.; Sönmez, Y.; Yörükeren, N. Optimal power flow using gravitational search algorithm. Energy Convers. Manag. 2012, 59, 86-95. [CrossRef]

10. Bhattacharya, A.; Roy, P.K. Solution of multi-objective optimal power flow using gravitational search algorithm. IET Gener. Transm. Distrib. 2012, 6, 751-763. [CrossRef]

11. Jahan, M.S.; Amjady, N. Solution of large-scale security constrained optimal power flow by a new bi-level optimisation approach based on enhanced gravitational search algorithm. IET Gener. Transm. Distrib. 2013, 7, 1481-1491. [CrossRef]

12. El-Sehiemy, R.A.; Shaheen, A.M.; Farrag, S.M. Solving multi-objective optimal power flow problem via forced initialised differential evolution algorithm. IET Gener. Transm. Distrib. 2016, 10, 1634-1647.

13. Varadarajan, M.; Swarup, K.S. Solving multi-objective optimal power flow using differential evolution. IET Gener. Transm. Distrib. 2008, 2, 720-730. [CrossRef]

14. Pulluri, H.; Naresh, R.; Sharma, V. A solution network based on stud krill herd algorithm for optimal power flow problems. Soft Comput. 2016, 5, 1-18. [CrossRef]

15. Adaryani, M.R.; Karami, A. Artificial bee colony algorithm for solving multi-objective optimal power flow problem. Int. J. Electr. Power Energy Syst. 2013, 53, 219-230. [CrossRef]

16. Ghanizadeh, A.J.; Mokhtar, G.; Abedi, M.; Gharehpetian, G.B. Optimal power flow based on imperialist competitive algorithm. Int. Rev. Electr. Eng. 2011, 6, 1847-1852.

17. Bhattacharya, A.; Chattopadhyay, P.K. Application of biogeography-based optimisation to solve different optimal power flow problems. IET Gener. Transm. Distrib. 2011, 5, 70-80. [CrossRef] 
18. Warid, W.; Hizam, H.; Mariun, N.; Abdul-Wahab, N.I. Optimal power flow using the Jaya algorithm. Energies 2016, 9, 678. [CrossRef]

19. Radosavljević, J.; Klimenta, D.; Jevtić, M.; Arsić, N. Optimal power flow using a hybrid optimization algorithm of particle swarm optimization and gravitational search algorithm. Electr. Power Compon. Syst. 2015, 43, 1958-1970. [CrossRef]

20. Bouchekara, H.R.; Chaib, A.E.; Abido, M.A.; El-Sehiemy, R.A. Optimal power flow using an improved colliding bodies optimization algorithm. Appl. Soft Comput. 2016, 42, 119-131. [CrossRef]

21. Arul, R.; Ravi, G.; Velusami, S. Solving optimal power flow problems using chaotic selfadaptive differential harmony search algorithm. Electr. Power Compon. Syst. 2013, 41, 782-805. [CrossRef]

22. Bouchekara, H.R.E.H.; Abido, M.A.; Boucherma, M. Optimal power flow using teaching learning- based optimization technique. Electr. Power Syst. Res. 2014, 114, 49-59. [CrossRef]

23. Bouchekara, H.R. Optimal power flow using black-hole-based optimization approach. Appl. Soft Comput. 2014, 24, 879-888. [CrossRef]

24. Lai, L.L.; Ma, J.T.; Yokoyama, R.; Zhao, M. Improved genetic algorithms for optimal power flow under both normal and contingent operation states. Int. J. Electr. Power Energy Syst. 1997, 19, 287-292. [CrossRef]

25. Attia, A.-F.; Sehiemy, R.A.E.; Hasanien, H.M. Optimal power flow solution in power systems using a novel Sine-Cosine. Int. J. Electr. Power Energy Syst. 2018, 99, 331-343. [CrossRef]

26. Surender, R.S.; Srinivasa, R.C. Optimal power flow using glowworm swarm optimization. Int. J. Electr. Power Energy Syst. 2016, 80, 128-139. [CrossRef]

27. Kumari, M.S.; Maheswarapu, S. Enhanced genetic algorithm based computation technique for multi-objective optimal power flow solution. Int. J. Electr. Power Energy Syst. 2010, 32, 736-742. [CrossRef]

28. Surender, R.S. Solution of multi-objective optimal power flow using efficient meta-heuristic algorithm. Electr. Eng. 2017, 100, 401-413.

29. Surender, R.S.; Abhyankar, A.R.; Bijwe, P.R. Reactive power price clearing using multi-objective optimization. Energy 2011, 36, 3579-3589.

30. Surender, R.S. Security constrained optimal power flow with FACTS controllers using hybrid differential evolution and harmony search algorithm. Int. J. Appl. Eng. Res. 2016, 11, 10939-10944.

31. Surender, R.S.; Bijwe, P.R. Differential evolution-based efficient multi-objective optimal power flow. Neural Comput. Appl. 2017, 31, 509-522. [CrossRef]

32. Abhishek, R.; Malakar, T. Optimal reactive power dispatch using hybrid Nelder- Mead simplex based firefly algorithm. Int. J. Electr. Power Energy Syst. 2015, 66, 9-24.

33. Chaib, A.E.; Bouchekara, H.R.; Mehasni, R.; Abido, M.A. Optimal power flow with emission and non-smooth cost functions using backtracking search optimization algorithm. Int. J. Electr. Power Energy Syst. 2016, 81, 64-77. [CrossRef]

34. Niknam, T.; Narimani, M.; Jabbari, M.; Malekpour, A.R. A modified shuffle frog leaping algorithm for multi-objective optimal power flow. Energy 2011, 36, 6420-6432. [CrossRef]

35. Sayah, S.; Zehar, K. Modified differential evolution algorithm for optimal power flow with non-smooth cost functions. Energy Convers. Manag. 2008, 49, 3036-3042. [CrossRef]

36. Yang, X.S.; Deb, S. Cuckoo search via Lévy flights. In Proceedings of the 2009 World Congress on Nature \& Biologically Inspired Computing, Coimbatore, India, 9-11 December 2009; pp. 210-214.

37. Yang, X.S.; Deb, S. Engineering optimisation by cuckoo search. Int. J. Math. Model. Num. Optim. 2010, 1, $330-343$. [CrossRef]

38. Gomes, G.F.; Cunha, S.S.A.; Ancelotti, A.C. A sunflower optimization (SFO) algorithm applied to damage identification on laminated composite plates. Eng. Comput. 2018, 35, 619-626. [CrossRef]

39. MATPOWER A MATLAB Power System Simulation Package Version 4.1. Available online: http://www. pserc.cornell.edu//matpower/ (accessed on 1 June 2020).

(C) 2020 by the authors. Licensee MDPI, Basel, Switzerland. This article is an open access article distributed under the terms and conditions of the Creative Commons Attribution (CC BY) license (http://creativecommons.org/licenses/by/4.0/). 